\title{
Investigation and Analysis on Group Quality Characteristics of College Students with High-quality Employment
}

\author{
Xiao-liang $\mathrm{GUO}^{1}$, Mei-juan FANG ${ }^{2}$ and Hong-bo $\mathrm{SHI}^{2, *}$ \\ ${ }^{1}$ School of Marxism, Harbin Institute of Technology, Weihai, Shandong 264209, China \\ ${ }^{2}$ School of Economics and Management, Harbin Institute of Technology, Weihai, Shandong 264209, China \\ *Corresponding author. Email: shihongbo@hit.edu.cn
}

\begin{abstract}
The employment quality of college graduates has aroused widespread concern in the society. Based on the literature review, this paper uses the questionnaire survey method, takes the officially contracted college students as the research object, and uses SPSS 22.0 software to analyze the survey results. It is concluded that the general quality characteristics of high-quality employment college students are: good physical quality, certain organizational ability, professional ability and practical ability, as well as good interpersonal skills. Keywords: college students; high-quality employment; quality characteristics
\end{abstract}

\section{INTRODUCTION}

Employment is the foundation of people's livelihood. The report of the 19th National Congress of the Communist Party of China further pointed out the need to "promote the realization of higher quality employment" while continuing to pay attention to the issue of employment.

\subsection{Research Background}

Xin Changxing once pointed out that "higher quality employment" mainly refers to sufficient employment opportunities, fair employment environment, better employability, reasonable employment structure, and harmonious labor relations, etc. [1]. It is of great theoretical and practical significance to study the employment quality of college graduates.

Whether at the macro or micro level, the starting point of most literature research is practical problems such as high employment pressure or difficult employment. Some scholars also adopt reverse thinking and pay more attention to the employees themselves. For example, collect typical cases of employment college graduates, discuss the nonintellectual factors affecting graduates' employment, and explore the psychological characteristics of successful employment college students. Most of these efforts are to explore the influencing factors of successful employment from one aspect [2].

Taking the contracted college students as the survey object, this paper studies the influencing factors and general characteristics of college students' successful employment, so as to serve as the decision-making basis for colleges and universities to promote college students' high-quality employment.

\subsection{Research Status at Home and Abroad}

Since the topic of high-quality employment was put forward only in recent years, there are few relevant studies at home and abroad. The following mainly introduces the research on college students' employment and college students' quality and ability.

In 1976, Freeman found the problem of the continuous decline in the rate of return on education in the United States since the 1970s, and put forward the concept of over education in his book The Over Educated American. The book points out that there is the problem of over education in varying degrees in both developing and developed countries, and draws many useful conclusions. Generally speaking, if college graduates can accurately predict their situation and possible work level in the ladder of labor market competition, they can make a reasonable career orientation [3].

Betts completed the report on the expected income of 1269 students at the University of California. Dominitz and Manski jointly completed the study on the expected income of 110 college and high school students in Wisconsin. The conclusions are as follows: usually college students overestimate their salary level and competitiveness; compared with the junior students, the senior and graduating students have stronger expectation ability and tend to be more rational at the same time; due to the influence of family background, gender, job search information source, school, grade, major, achievement and other factors, there are great differences in income expectation [4].

Wang Hongcai and Xie Weihe (2001) analyzed the statistical data from 1996 to 1998, and explored the talent demand of various majors and the overall characteristics of social demand. In addition, they also introduced the 
employment situation of college graduates affiliated to the Ministry of Education [5]. The survey results of Ma luting (2002) show that enterprises pay more attention to the quality and ability of graduates, and there are great differences in the professional positions and adaptability of graduates at different levels [6]. He Xiang and Dong Lei, etc. (2016) investigated the 2016th graduates of Northeast University and reached the following conclusions: the main personal comprehensive qualities of graduates valued by employers include the ability to master knowledge, the ability to solve professional problems, the ability to express and communicate, the ability to integrate, the ability to execute, the ability to work in team creativity and innovation, and the ability to find and solve problems. The level of personal comprehensive quality directly affects the success or failure of college students' job hunting [7].

Schroeder and Fredric (2007) believe that high-quality employment refers to an individual's ability to obtain the salary needed to make a living in the comprehensive environment of his challenging and satisfactory work. Decent work is closer to high-quality employment in connotation. The employment quality has a ladder like two-way mobility, that is, workers with low-quality employment may transfer to high-quality employment, and vice versa [8]. Scholars believe that the narrow concept of the quality of employment has been consistent with the narrow concept of the quality of income obtained in the whole process of employment. Guo Fuli holds a view that high-quality employment should be a free, not forced, equal opportunity, safe, dignified and equal pay job for workers [9].

\section{QUALITY CHARACTERISTICS QUESTIONNAIRE COLLECTION AND DATA ANALYSIS}

\subsection{Questionnaire Design}

\subsubsection{Questionnaire Content}

The questionnaire survey of this paper is mainly divided into three parts.

- Basic personal information: understand the basic information of the respondents such as gender, age, political outlook, family conditions, family background, work city, work industry and love situation.

- Employment satisfaction survey: investigate the job satisfaction of the respondents to determine whether they are high-quality employment, including salary level, welfare benefits, sense of achievement brought by work, fit between work and specialty, development space and work intensity.
- Basic quality: investigate the physical quality, organizational ability, professional ranking, practical ability and interpersonal communication ability of the respondents, and explore their basic qualities.

\subsubsection{Specific Distribution of Questionnaire Items}

The specific distribution of questionnaire items in this study is shown in Table 1 .

Table 1. Number of Questionnaire Items and Distribution of Various Factors

\begin{tabular}{|c|c|c|}
\hline $\begin{array}{c}\text { Questionnaire } \\
\text { Part }\end{array}$ & Factor Index & $\begin{array}{c}\text { Topic } \\
\text { Distribution }\end{array}$ \\
\hline \multirow{8}{*}{$\begin{array}{l}\text { Personal } \\
\text { information }\end{array}$} & Gender & 1 \\
\hline & Age & 2 \\
\hline & Political outlook & 22 \\
\hline & Family conditions & 9 \\
\hline & Family background & 10 \\
\hline & Work city & 5 \\
\hline & Work industry & 8 \\
\hline & Love situation & 21 \\
\hline \multirow{6}{*}{$\begin{array}{l}\text { Employment } \\
\text { satisfaction }\end{array}$} & Pay level & $7(1)$ \\
\hline & Fringe benefits & $7(2)$ \\
\hline & $\begin{array}{l}\text { The sense of } \\
\text { achievement brought } \\
\text { by work }\end{array}$ & $7(3)$ \\
\hline & $\begin{array}{l}\text { Fit between work and } \\
\text { specialty }\end{array}$ & $7(4)$ \\
\hline & Development space & $7(5)$ \\
\hline & Working intensity & $7(6)$ \\
\hline \multirow{5}{*}{ Basic quality } & Physical quality & $11 \sim 15$ \\
\hline & Organization skills & 16,17 \\
\hline & Professional ability & $18,23,24$ \\
\hline & Practical ability & $19,20,23,24$ \\
\hline & Interpersonal skills & $16,17,23$ \\
\hline
\end{tabular}

\subsection{Statistics of Basic Personal Information of Respondents}

The statistical content of the basic information of the respondents mainly includes six parts: gender distribution, age distribution, political outlook, family situation, love situation and basic work situation. And analyze the relevant data respectively.

\subsubsection{Gender and Age}

The gender distribution of the questionnaire is relatively balanced; with boys accounting for $54.72 \%$ and girls accounting for $45.28 \%$.Young people aged $20 \sim 25$ were the 
main respondents, accounting for $81.13 \%$ of all data. This questionnaire is mainly aimed at the college students who have signed a contract or have just started working.

\subsubsection{Political Outlook}

The total proportion of Party members and probationary party members is only $13.79 \%$, accounting for a small part. During the campus life, the number of recruiting party members is limited. Generally, there are rigid requirements for grades, such as no failing courses and credit scores higher than 80 points. Therefore, most of the employed college students' scores are not very high, and there may even be a possibility of failing the course.

\subsubsection{Family Situation}

It can be seen that most families belong to the upper middle level. The survey asked whether it was a single parent family. The results showed that $90 \%$ were two parent families. Therefore, relatively speaking, most of the respondents have good family conditions and family background, and have a relatively happy family life.

\subsubsection{Love Situation}

The proportion of respondents who fell in love during college is basically the same as that who did not fall in love. Relatively speaking, whether they fall in love or not has little impact on their employment. Most people who have been in love have only one experience.

\subsubsection{Basic Information of Work}

The questionnaire setting of working cities is mainly divided into domestic and foreign cities, inland and coastal cities, first tier cities, second tier cities and third tier cities. The data show that almost all the respondents work in domestic cities, most of them work in the first and second tier cities, and very few in the third tier cities. It can be seen that there is also a certain positive correlation between the quality of employment and the employment city.

\subsection{Descriptive Statistics}

Through the online survey, 147 valid questionnaires were collected. The data were analyzed by SPSS 22.0 software. Due to space limitation, relevant tables are omitted.

\subsection{Reliability and Validity of Questionnaire}

This study uses the questionnaire to investigate the basic quality of employed college students. The authenticity and applicability of this study are determined by the quality of the questionnaire design content. Therefore, to ensure the validity of the questionnaire, the reliability and validity of the obtained data will be analyzed.

\subsubsection{Reliability Analysis}

The reliability coefficient method was used to test the reliability of the questionnaire. The greater the reliability coefficient, the higher the reliability of the questionnaire. In the field of social science research, if the total reliability coefficient of the questionnaire is more than 0.8 and the reliability coefficient of the sub questionnaire is more than 0.7 , it can be considered that the reliability is good; if the reliability coefficient of the sub questionnaire is between 0.6 and 0.7 , the questionnaire is still acceptable. However, when the total reliability coefficient of a questionnaire is less than 0.8 or its sub questionnaire coefficient is less than 0.6 , the questionnaire needs to be revised.

SPSS 22.0 software is used to conduct reliability analysis (i.e. reliability analysis) on the questionnaire related data of this study. The results are shown in Table 2. It can be seen that the questionnaire has high reliability.

Table 2. Reliability Statistics

\begin{tabular}{|c|c|c|}
\hline $\begin{array}{c}\text { Cronbach's } \\
\boldsymbol{\alpha}\end{array}$ & $\begin{array}{c}\text { Cronbach's } \boldsymbol{\alpha} \text { Based on } \\
\text { Standardized Terms }\end{array}$ & $\begin{array}{c}\text { Number } \\
\text { of Items }\end{array}$ \\
\hline 0.821 & 0.760 & 61 \\
\hline
\end{tabular}

\subsubsection{Validity Analysis}

This study will use factor analysis for validity analysis. Before factor analysis, KMO (Kaiser Meyer Olkin) sampling suitability measurement and Bartlett's test of sphericity shall be conducted to judge whether the questionnaire is suitable for factor analysis. KMO test is used to detect the partial correlation between variables. When the statistic is above 0.7 , the effect of factor analysis is better; when the statistics are below 0.5, the effect of factor analysis is very poor.

KMO and Bartlett spherical test were performed on the questionnaire with SPSS 22.0 software. The data obtained are shown in Table 3 .

Table 3. KMO and Bartlett's Test

\begin{tabular}{|c|c|c|}
\hline \multicolumn{2}{|c|}{$\begin{array}{c}\text { Kaiser Meyer Olkin Measure of } \\
\text { Sampling Adequacy }\end{array}$} & 0.863 \\
\hline \multirow{3}{*}{$\begin{array}{c}\text { Bartlett Spherical } \\
\text { Test }\end{array}$} & $\begin{array}{c}\text { Approximate } \\
\text { chi square }\end{array}$ & 739.541 \\
\cline { 2 - 3 } & $\boldsymbol{d f}$ & 15 \\
\cline { 2 - 3 } & Sig. & 0.000 \\
\hline
\end{tabular}

It can be seen from Table 3 that the KMO test value of the questionnaire is 0.863 , greater than 0.7 , and the $p$ value of Bartlett's spherical test significance level is 0, indicating that there is a correlation between various variables. 


\section{GROUP QUALITY CHARACTERISTICS OF COLLEGE STUDENTS WITH HIGH- QUALITY EMPLOYMENT}

\subsection{Analysis on the Concept of Quality Characteristics}

Researchers do not have the same scope and focus on the definition of the concept of quality. After summing up, we can get the following three points: (1) quality is a deepseated internal characteristic of people and the result of the interaction between congenital and acquired, (2) quality is related to the distinction between effectively completing work and high performance, and (3) quality is mainly reflected in people's behavior. It has relatively stable characteristics and can be measured [10].

Quality characteristics refer to the individual potential characteristics that have some causal relationship with the reference index. Generally speaking, quality is an individual's deep-seated characteristics. It refers to the characteristics that can distinguish the average performance from the excellent performance in a certain work. This paper mainly discusses some basic abilities of the subjects, and analyses the group quality characteristics of highquality employment college students [11].

\subsection{Statistical Analysis of Basic Quality of Respondents}

The basic qualities of the subjects investigated in this questionnaire mainly include: physical quality, organizational ability, professional ability, practical ability, interpersonal communication ability, etc.

\subsubsection{Physical Quality}

The understanding of the physical quality of the respondents in this questionnaire mainly includes four aspects: physical health status, exercise frequency, sleep quality and work and rest time. Data shows that most people are in good health. It can be seen that less than one third of people do not spend time on physical exercise. Among them, most of the groups who spend time on exercise every day spend less than 1 hour a day on average. According to the statistical data, almost all of them have good sleep quality and regular work and rest time. Sleep quality determines people's mental state substantially.

\subsubsection{Organization Skills}

Organizational ability is mainly reflected by the positions held during college, and high school. From the data analysis, it can be found that more than $85 \%$ of them have held certain positions during high school, and the positions are generally related to their grades, which means that these groups have relatively good grades in high school. During the college life, the proportion of not holding any position is twice as high as that in high school. The choice of positions in college has a certain autonomy, which is closely related to their own will. At the same time, various positions in college have a good training effect on their own organization and leadership ability.

\subsubsection{Professional Ability}

Professional ability is mainly reflected by the ranking of achievements during the campus life. According to the survey data, it can be seen that the proportion of majors ranking in the top $10 \%$ is very small. This is because the top $10 \%$ of students have the qualification of postgraduate admission, and the possibility of giving up this resource to choose employment is still very slim. The proportion of majors ranking at about $50 \%$ is very high. Employed college students generally spend a lot of time exercising their abilities in school, spend less time on learning than others, and even choose to skip classes because of other affairs. Their achievements are relatively low, while they also have a certain grasp of professional knowledge.

\subsubsection{Practical Ability}

The practical ability is mainly reflected by the competitions participated in on campus. Moreover, college students can also improve their level in all aspects through the process of competition preparation, and the final award result is an affirmation of their ability. The data show that most of the respondents have participated in various types of competitions, and most of them have won awards, which reflect their certain practical ability. Most people's awardwinning areas mainly focus on study, followed by social activities and community organizations, which further shows that such groups have not affected learning performance while participating in various activities.

\subsubsection{Interpersonal Skills}

The interpersonal skills during college can be reflected in the data. First of all, having certain organizational ability and holding various positions means that they can effectively communicate and coordinate with classmates, teachers and even social people outside the school. Their interpersonal skills must be higher than ordinary people. Secondly, have a certain practical ability. In the process of participating in various types of competitions and winning awards, on the one hand, you need to have good communication with your peers to achieve a good tacit understanding. On the other hand, the more competitions you participate in, the more people around you will have a higher sense of worship for such groups. And as a result, 
their sense of pride will be enhanced, thus becoming more confident, and their interpersonal skills will be stronger.

\section{CONCLUSION}

This paper mainly judges whether the employed college students are high-quality employed from six aspects: salary level, welfare treatment, sense of achievement brought by work, fitness between work and specialty, development space and work intensity. According to the data obtained, most of them are at the level of high-quality employment. Therefore, the following investigation on the basic quality of this group is credible.

Based on the data analysis, to conclude, some basic quality characteristics of high-quality employment college students can be obtained, including:

- Have good physical quality. During college, one should be healthy and spend some time on exercise to improve his/her physical quality. In addition, in the atmosphere of more free time on campus, they can still maintain regular work and rest time balanced, making their mental state vigorous.

- Have certain organizational ability. During the university, he took the initiative to hold class positions, organized class activities, participated in various organizations and associations, and would try his best to win leadership positions. Therefore, it can exercise the organizational leadership ability.

- Have certain professional ability. According to the survey, it can be found that most of the scores of these groups are at the upper middle level, which has something to do with the fact that the top $10 \%$ $20 \%$ of the majors have the opportunity to obtain postgraduate admission. But relatively speaking, they also need to master professional knowledge.

- Have certain practical ability. Participating in various types of competitions and winning awards during college is an affirmation of their practical ability. The students generally take some time to prepare, and learn new software or tools.

- Have good interpersonal skills. Such groups participate in more social activities and hold various positions, which require them to deal with all kinds of people. This has a significant effect on their interpersonal skills.

\section{ACKNOWLEDGMENT}

Sponsored by the fundamental research funds for the central universities (HIT.HSS.HXJS202006), Shandong social sciences planning research project (18CRCJ13) and the Ministry of Education humanities and social sciences research project special task (18JDGC014).

\section{REFERENCES}

[1]Changxing Xin. "Strive to promote higher quality employment" [J]. Chinese Journal of Population Science, 2012, (6): 2-5. (In Chinese)

[2]Xin Guo, Qingya Wang. "Generation mechanism and guiding strategy of college students' employment values" [J]. Ideological and Political Education Research, 2021, 37(2): 120-123. (In Chinese)

[3]Wenjie Liu. "Research on the phenomenon of 'over education' in China" [J]. Journal of Inner Mongolia Normal University (Educational Science Edition), 2013, 26(8): 5-8. (In Chinese)

[4]Ming Zhao. "Research on the countermeasures to improve the employment quality of college students in China" [J]. Jiangsu Higher Education, 2019, (10): 67-72. (In Chinese)

[5]Juan Wang. "Research on the employment of college students in private colleges and universities in China". Nanjing University of Science and Technology, 2011. (In Chinese)

[6]Luting Ma. "Employment and evaluation of college graduates by employers" [J]. Journal of Higher Education, 2002, (1): 43-47. (In Chinese)

[7]Xiang He, Lei Dong, Wei Zhang, Miao Shang. "Improving the employment core competitiveness of science and engineering students guided by high-quality employment" [J]. The Guide of Science \& Education. 2016, (29): 179-181. (In Chinese)

[8]Fuli Guo. "Discussion on the quality of foreign labor field: related categories of employment quality" [J]. Journal of Beijing Institute of Administration, 2009, (1): 86-91. (In Chinese)

[9]Fuli Guo. "Review of domestic research on employment quality: meaning, quantitative evaluation and influencing factors" [J]. China's Collective Economy, 2008, (24): 28-29. (In Chinese)

[10]Yurong Li, Huijing Li. "Analysis on the cultivation of college students' comprehensive quality based on competency model" [J]. Heilongjiang Research on Higher Education, 2015, (9): 141-144. (In Chinese)

[11]Kai Bai, Jianling Li. "Review on the research status of entrepreneurs' quality characteristics abroad" [J]. China Youth Study, 2012, (4): 80-83. (In Chinese) 